\title{
Effects of easy listening music intervention on satisfaction, anxiety, and pain in patients undergoing colonoscopy: a pilot randomized controlled trial
}

This article was published in the following Dove Press journal:

Clinical Interventions in Aging

\section{Shuk Yee Ko' \\ Doris YP Leung ${ }^{2}$ \\ Eliza ML Wong ${ }^{2}$}

'Accident and Emergency Department, Tuen Mum Hospital, Tuen Mun, NT, Hong Kong; ${ }^{2}$ School of Nursing, The Hong

Kong Polytechnic University, Hung Hom, Kowloon, Hong Kong

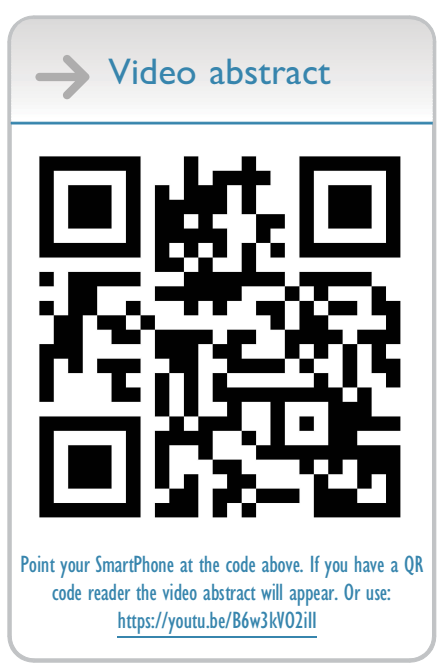

Correspondence: Eliza ML Wong School of Nursing, The Hong Kong Polytechnic University, Hung Hom, Kowloon GH 521, Hong Kong

Tel +8522766 6544

Fax +85223649663

Email eliza.wong@polyu.edu.hk
Purpose: The purpose of this study was to examine the effects of an easy listening music intervention on satisfaction, anxiety, pain, sedative and analgesic medication requirements, and physiological parameters in Chinese adult patients undergoing colonoscopy in Hong Kong. Patients and methods: Patients undergoing colonoscopy, aged 45 or older, able to communicate in Chinese, and hemodynamically stable were invited for the study. A randomized controlled trial was adopted. Eligible patients were randomly assigned either to a music group, which received standard care and additional easy listening music (a series of 15 popular non-rock Chinese songs) through earphones and MP3 for 20 mins before and during the procedure, or to a control group which received standard care only. Standard care comprised of all nursing and medical care provided for patients undergoing colonoscopy. Measures comprised of the State-Trait Anxiety Inventory, visual analog scales of pain level, procedure satisfaction and satisfaction with pain management, the use of sedative and analgesic drugs, heart rate, and blood pressure data were collected at baseline (T0), during (T1) and 30 mins after the procedure (T2).

Results: Eighty participants (40 music vs 40 control) completed the study with no attrition. Participants in the music group reported significantly higher levels in both procedure satisfaction $(p=0.043)$ and satisfaction with pain management $(p=0.045)$ than those in the control group. No significant difference was found between groups on anxiety, pain, additional sedative and analgesic use, heart rate, and systolic and diastolic blood pressure $(p>0.05)$. Nevertheless, most participants appreciated the songs provided in MP3 and found it helpful for relaxation during the procedure and would prefer it again $(p<0.001)$.

Conclusion: Easy music listening can enhance patients' satisfaction in both procedure and pain management for adults undergoing a colonoscopy procedure.

Keywords: colonoscopy, easy listening music, satisfaction, anxiety, pain

\section{Introduction}

Colonoscopy is an endoscopy examination of the large bowel and the distal part of the small bowel, which is the most common procedure and gold standard used in the diagnosis of cancer colon and in the treatment of diseases of the lower gastrointestinal tract such as removal of polys or removal suspected malignant lesions. ${ }^{1,2}$ However, the procedure is unpleasant and often causes patients anxiety and pain due to abdominal discomfort and a sensation of fullness. ${ }^{3-7}$ 
Recent studies reported that $75 \%$ of pre-operative surgical patients are anxious ${ }^{8,9}$ and over $40 \%$ report moderate pain or severe pain during colonoscopy. ${ }^{10}$ Patients' anxiety regarding colonoscopy may result from the strangeness of the hospital environment, a lack of knowledge regarding the procedure, the uncertainty of the outcome, fear of pain and worry about the recovery process. ${ }^{2-4}$ High levels of anxiety and pain may result in a more difficult procedure, an increased need for sedative and analgesic medication, an increased likelihood of medication-related complications and an incomplete examination, low patient satisfaction rate and negative physiological manifestations such as increased blood pressure and heart rate. ${ }^{8,9,11,12}$

Nowadays, colonoscopy under full sedation is used to ensure smooth procedure and alley patients' anxiety. However, this type of pharmacological intervention may have some side effects: it may increase the risk of cardiopulmonary complication especially for aging patients; result in hemodynamic instability; lead to undesirable side effects such as nausea, vomiting, respiratory depression and drowsiness; and/or the sedative may interact with anaesthetic agents, prolong patients' recovery and delay discharge from hospital. ${ }^{6,10,11}$ In this regard, conscious sedation with minimal sedative (Midazolam) and analgesic medications (Fentanyl) are also commonly adopted used in the government hospital for colonoscopy worldwide and in Hong Kong. Non-pharmacological interventions such as listening to music to reduce above complications are recommended globally. ${ }^{4,6,7,10}$

In recent years, music has been recognized for the therapeutic use in health care. Music therapy has been reported to promote relaxation, reduce pain, improve satisfaction and reduce mean arterial pressure and heart rate in sigmoidoscopy or colonoscopy. ${ }^{6,7,10,13-19}$ A review of the literature indicates that listening to music has a statistically significant effect on reducing pain and anxiety preceding during, and up to 2 days post-surgery without causing any harmful effects. ${ }^{10,18}$ Thus, it is reasonable to offer this non-invasive modality to patients during colonoscopy in the clinical settings.

Several studies have demonstrated a beneficial effect of music during colonoscopy, such as its ability to reduce anxiety and pain levels during the procedure. ${ }^{6,13-19}$ However, most previous studies did not provide specific information about the components of music intervention, such as the type of music, its volume or duration., ${ }^{4,6,18}$ This has led to a gap in our knowledge of the specific variables that are most effective in producing positive outcomes related to anxiety, sedative and analgesic medication requirements, blood pressure and procedure satisfaction. Light music or classical music have been the styles of music most commonly used in the clinical setting. Previous literature suggests the adoption of soft music with stable melodies at a tempo of $60-80$ beats per minute regarded as the most effective type of music. ${ }^{10} \mathrm{~A}$ recent trial reported the comparison of informal classical music and light music on outcomes in Chinese patients undergoing colonoscopy without sedation ${ }^{1}$. Songs such as "Canon in D" from the album "Pachelbel by The Sea" by David Tolley were recognized as the genre of informal classical music, or songs such as "Blossom on the Wind" from the album "Embracing The Wind" by Kevin Kern were recognized as the genre of light music. The result was inconclusive although listening to light music had a trend of reducing the level of anxiety in patients undergoing colonoscopy examination without sedation. ${ }^{1}$ To the best of our knowledge, no study has specifically focused on the effects of easy listening music intervention on outcomes in adults undergoing colonoscopy. "Easy-listening" music is the name given to the type of music which has a soft melody and is nonpercussive in beat. The music adopt more use of strings. ${ }^{21}$ Since music preference varies in different age group, and type of music intervention may confound the intervention dosage and outcomes, there is a need to have an empirical trial to examine the effects of easy music intervention on physiological and psychological outcomes, and requirements for sedative and analgesic medication in patients undergoing colonoscopy with minimal sedation. ${ }^{1,22,23}$ The purpose of this study was to examine the effects of an easy listening music intervention on satisfaction, anxiety, pain, sedative and analgesic medication requirements and physiological parameters in terms of blood pressure and pulse rate in Chinese adult patients undergoing colonoscopy in Hong Kong. In this study, we selected those easy listening music from a musical genre that is most popular and related to Cantonese hit songs and popular non-rock vocals. ${ }^{21,24}$

\section{Theoretical framework of music intervention}

The stress and coping theory of Lazarus and Folkman (1984) was used to guide this study because it has been widely used in many studies. ${ }^{13,25-28}$ Based on this theory, the colonoscopy procedure acts as a stressor for the patients in this study because patients often experience anxiety and pain due to the unfamiliar environment, previous negative experience with medical procedures and decreasing tolerance and pain thresholds. ${ }^{13,27,28}$ Anxiety and pain are common problems associated with colonoscopy $y^{1,7}$ and colonoscopy is also 
associated with emotional distress and physical discomfort. ${ }^{5,10}$ When confronted with this stressor, patients choose available measures to decrease their physiological discomfort and psychological distress, such as listening to music and receiving sedative and analgesic drugs. Because music acts as a distractor; it can occupy the mind with something pleasant, and take a person's attention away from a negative experience and replace it with positive thoughts. ${ }^{25,26}$ In addition, the music component has the capacity of adjusting emotional states and promotes mind-body interactions and was widely accepted for promoting relaxation in the health care. ${ }^{1,15}$ Finally, successful coping (the effect of music) can be reflected by physical health (pain, the need for sedative and analgesic medications, heart rate and blood pressure) and psychological well-being (levels of anxiety and satisfaction).

\section{Material and methods Design and randomization}

A prospective parallel, randomized controlled trial with two groups: the music group versus control group. The music group received standard care plus a series of easy listening music before and during the procedure while the control group received only standard care. A twogroup study design may yield reliable evidence about the interventional use of music vs standard care, and will allow us to directly investigate the cause and effects. This design is guided by the CONSORT checklist. $^{29}$ The study was conducted from March 2015 to August 2015.

\section{Study setting}

The study was conducted in the Electro-Medical Diagnostic Unit (EDU) of an acute general public hospital in Hong Kong. This unit is responsible for performing all endoscopic procedures such as colonoscopy, sigmoidoscopy, endoscopic retrograde cholangiopancreatography and esophagogastroduodenoscopy. There were five afternoon sections per week at the endoscopy unit for colonoscopy patients. About 5,000 colonoscopy procedures were conducted in this unit in $2014 .^{30}$

\section{Subjects and sample size}

For the pilot randomized controlled trial, Hertzog (2008) recommended that 30 to 40 participants per intervention or control group will be needed to obtain a direct estimate of a between-groups effect size for a subsequent power analysis. ${ }^{31}$ Thus, the sample size for this pilot study was set at 80 .
Inclusion criteria for participants included: (a) patients scheduled for colonoscopy; (b) able to communicate in Chinese language; (c) hemodynamic stable before colonoscopy. Participants with visual and hearing deficits, or a medical history of dementia, cognitive disorders or psychiatric disorders were excluded.

\section{Randomization and masking}

Eligible participants were randomly allocated to either intervention group (I) or control group (C). Blocked randomization with a block size of eight was used to maintain a good balance of participants between the two groups throughout the subject recruitment period. A sequence group ( $\mathrm{I}$ or $\mathrm{C}$ ) based on computer-generated random codes was prepared in advance and put in serially numbered opaque sealed envelope by a person independent to the study. The envelope was opened sequentially for each consented participant who had completed the baseline data collection. In this study, a research assistant who served as outcome assessor was blinded to the allocation sequence. Given the type of intervention, the participants, health care staff and the principal investigator who performed the music intervention were unmasked of the allocation of the intervention.

\section{Intervention}

\section{Standard care}

All patients received standard care and bowel preparation before the colonoscopy, which consisted of a residue diet for 3 days before the procedure and a fluid diet in conjunction with a bowel-cleansing agent (Klean-prep) the evening before the investigation. The morning of the colonoscopy, all patients were admitted to the day ward for preparation, which included written informed consent for colonoscopy and establishment of a peripheral line for the administration of conscious sedation. After the patient was transferred to the Endoscopic unit, all patients usually took a rest and waited in the large pending area for about 20 mins waiting for their term. Then, patients would be transferred to the procedure area, conscious sedation with standard dose of minimal sedative (Midazolam) and analgesic medications (Fentanyl) was offered to the patient accordingly. Patients were given the option to request more analgesic on demand during the procedure. During the procedure, blood pressure and heart rate were closely monitored every 5 mins. All examinations were performed by an expert endoscopist using an Olympus CV-145videocolonoscope. 


\section{Intervention group}

The patients of the intervention group received standard care plus easy listening music intervention. In this study, the participants in the intervention group were offered 15 easy listening Chinese popular songs from the MP3. The selection of Chinese songs was based on the above principle and the selection from panel of 6 people (two part time musicians, three patients at age 45-65 and a nurse who studied music) and the record of most popular nonrock songs during 1990-2010. A headphone with MP3 was provided to the participants of the intervention group 20 mins before and during the procedure. 15 songs were repeatedly played via the MP3 player. The volume of the music was controlled by the patients. After the procedure, as indicated by withdrawal of the colonoscopy, the music was stopped and the earphones were removed immediately by the procedure nurse.

\section{Procedure and data collection}

In the day ward, potential eligible patients were approached by the principal investigator for further screening, and those deemed eligible were asked to sign consent form after explanation. Baseline data (T0) were collected prior to patient randomization. Randomization was based on the prior prepared random group allocation sequence. The procedure nurse of the hospital was responsible for the removal of the earphones after the completion of the procedure of colonoscopy. Another research assistant, who was blinded to the group assignment, performed data collection at $\mathrm{T} 2$. The research assistant was trained before the commencement of the study. Data were collected at T0 (after consent for study), T1 (5 mins after insertion of colonoscopy) and T2 (30 mins after completion of the colonoscopy) accordingly. Simultaneously, physiological parameters including heart rate and blood pressure were recorded at $\mathrm{T} 0, \mathrm{~T} 1$ and $\mathrm{T} 2$ by procedure nurses in the EDU.

\section{Ethical consideration}

Ethics approval had been obtained from the Joint Chinese University of Hong Kong and Clinical Research Ethical Committee, New Territories West Cluster, Hospital Authority, Hong Kong. RCT registration has been obtained with registration number (ClinicalTrials.gov RCT registration number is: CUHK_CCT00461). All participants had been well informed about the purpose and procedure of the study before signing a written informed consent form. Participants were told about the rights to withdraw at any time without detrimental effects. Confidentiality and anonymity were assured during the study.

\section{Measures}

Three consecutive (T0, T1 and T2) data collection were arranged and conducted for all participants. This arrangement was selected to facilitate easy comparisons with similar studies in the literature, as well as to ensure the feasibility of data collection. A validated structured questionnaire was used for data collection. The primary outcome and the secondary outcomes are listed below:

\section{Demographic and clinical data}

Demographic and clinical data from the participants, including gender, age and education level, previous experience of colonoscopy, regular follow-up and medication taking, personal history of carcinoma, family history of carcinoma were retrieved from the medical record.

\section{Anxiety}

Anxiety was measured after consent for study (T0), and 30 mins after completion of the colonoscopy (T2) by using the State Trait Inventory, Chinese version STAI-C. ${ }^{31,32}$ The STAI-C has two parts of 20 items each. The first part (state anxiety) evaluates a transitory emotional state that is influenced by intense emotional situations and varies in intensity over time. The second part (trait anxiety) demonstrates a relatively stable anxious tendency and is not significantly influenced by emotionally intense situations. Each item was rated on a 4-point Likert scale, ranging from 1 to 4, with sum of scores ranging from 20 to 80 , with higher scores indicating a higher level of anxiety. The STAI-C was validated in Hong Kong and was found to have a high degree of internal consistency $($ alpha $=0.9) .^{20,32,33}$

\section{Pain intensity, procedure satisfaction and satisfaction with pain management}

Pain intensity, procedure satisfaction and satisfaction with pain management were measured at $\mathrm{T} 2$ using visual analogue scales (VAS). A VAS is usually a $10 \mathrm{~cm}$ long horizontal line with verbal descriptors (word anchors) at each end and the respondent marks on the line that represents individual perception of the current state. The score was obtained by measuring the distance $(\mathrm{cm})$ from point 0 to the marked point ${ }^{34}$. The VAS has been shown to be a valid tool for the measurement of psychological and health variables such as pain and satisfaction which has been widely used in clinical trials. ${ }^{34-36}$ 


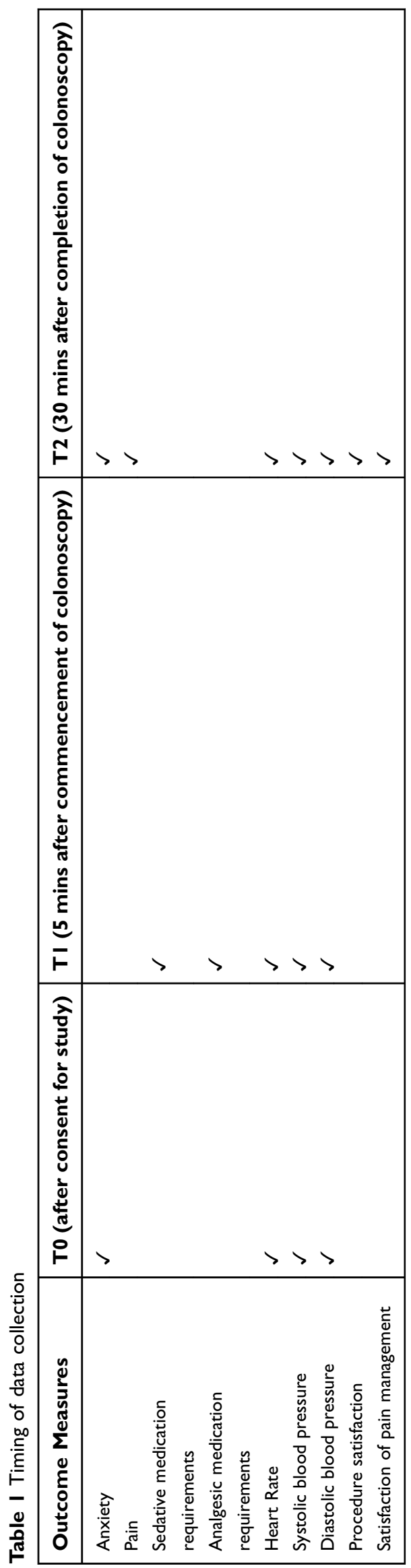

Additional sedative and analgesic use. Additional sedative and analgesic medication requirements during the procedure were retrieved from the medical record.

Physiological parameters. Physiological parameters (heart rate, systolic blood pressure and diastolic blood pressure) were measured at all the three time points $\mathrm{T} 0$, $\mathrm{T} 1$ and T2. Two further questions were used to ascertain participants' music preference and opinions of the music intervention. The timing of data collection was listed as in Table 1:

\section{Statistical analysis}

Data were analyzed using IBM SPSS 22.0 (IBM Crop., Armonk, NY). Descriptive statistics, including frequency, percentage, mean and standard deviation, were used to describe the data, as appropriate. Chi-square tests compared categorical variables and independent $t$-tests compared continuous variables at baseline to assess homogeneity of the groups. To examine the effectiveness of the easy listening music therapy, independent t-tests compared mean scores of pain, procedure satisfaction and satisfaction with pain management, chi-square tests compared proportions of the need for sedative and analgesic medication during the procedure and music preferences for colonoscopy and repeated measures of analysis of variance (RMANOVA) compared changes in anxiety, systolic and diastolic blood pressure and heart rate over time between the two groups. All the statistical tests were two-sided and level of significance was set at 0.05 .

\section{Results}

Data were collected from March 1, 2015, to August 31, 2015, in the EDU of an acute general hospital in HK. A total of 106 patients were assessed for eligibility, and 26 were excluded with 19 patients did not meet the eligibility criteria and 7 patients declined to participate in the study. A total of 80 patients underwent randomization with 40 patients in the music group and 40 in the control group. All participants completed the whole study, and none reported discomfort related to the music intervention (Figure 1). Mean age of the sample was 57 years, most participants had received secondary education or above (63.8\%), were living with family members (91.2\%) and had no previous colonoscopy experience $(53.8 \%)$ and had no personal history of cancer $(81.2 \%)$. No significant difference was found between the two groups with respect to demographic and clinical characteristics (Table 2).

Listening to music had significant effects on improving procedure satisfaction $(p=0.043)$ and satisfaction with pain 


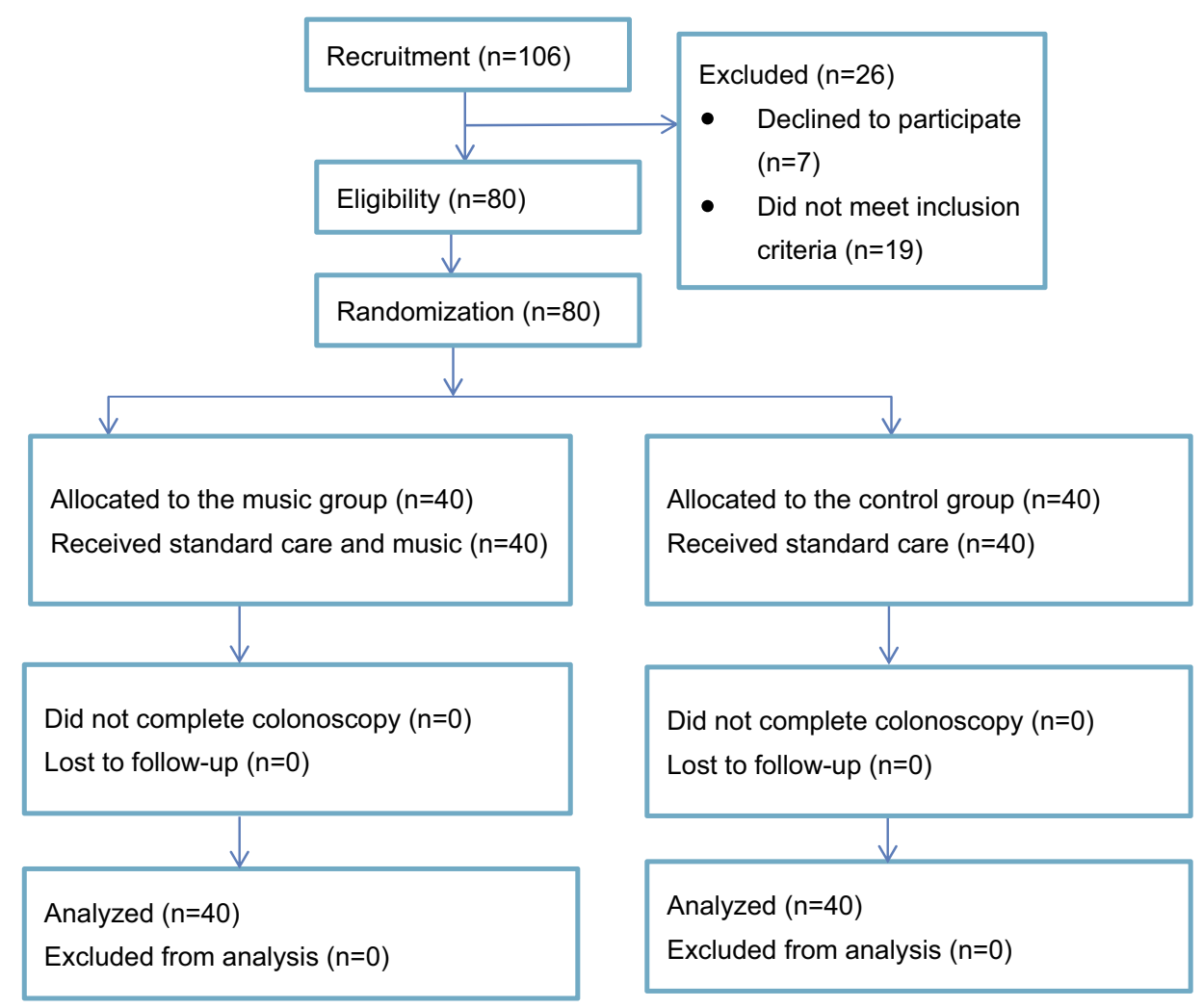

Figure I Flowchart of the study.

management $(p=0.045)$. Moreover, most participants indicated that they would choose to listen to music to reduce their anxiety during a future colonoscopy examination $(p=0.001)$.

There were no statistical differences between the two groups in terms of state anxiety, pain, heart rate and systolic and diastolic blood pressure. Regarding need of extra sedative and analgesic, music group requested less sedative $(15 \%$ vs $27.5 \%)$ and less analgesic $(17.5 \%$ vs $35 \%)$ compared to the control group although it is not statistically significance (Table 3 ).

\section{Discussion}

To the best of our knowledge, this is the first study to examine the effects of an easy listening music intervention on procedure satisfaction, satisfaction with pain management, anxiety, pain, sedative and analgesic medication requirements, and physiological parameters in Chinese adult patients undergoing colonoscopy.

Compared with the control group, patients in the music group reported a significantly higher level of satisfaction with pain management. The results were consistent with previous studies. ${ }^{1,7}$ Although the participants listened to different types of music, they consistently demonstrated an increased level of satisfaction. This finding further supports the idea that easy listening music can increase patient satisfaction. Regarding clinical significance, a difference of greater than $15 \mathrm{~mm}$ on a VAS pain scale would normally be perceived as clinically important or the request of significant less analgesic would also reflect the impact of clinically significance. ${ }^{34-36}$ In this study, our result of VAS scale mean difference between groups of both procedure satisfaction and pain satisfaction $(<10 \mathrm{~mm})$ and the request of analgesic showed no statistical significance. It may indicate that the intervention was not clinically significant especially for the pain management.

Although there was no statistical difference in the mean state anxiety levels between the two groups after colonoscopy, a trend of reducing level of anxiety was observed in the music group, which was consistent with other colonoscopy studies showing a reduction of anxiety when patients were offered to listen to music during the examination. ${ }^{1,18}$ Moreover, most of the participants indicated that they would want to have music available to them again during a future colonoscopy procedure.

The results of this study show that patients experienced moderate anxiety before the procedure. This is congruent with the results of previous studies. ${ }^{1,8,9,11}$ Negative feelings not only cause negative physiological manifestations, but can also increase the complications of medication administration. ${ }^{6,7}$ Thus, psychological assessment and 
Table 2 Demographic and clinical characteristic of the participants

\begin{tabular}{|c|c|c|c|c|}
\hline Group & $\begin{array}{l}\text { Total, } \mathbf{n} \\
\text { (\%) }\end{array}$ & $\begin{array}{l}\text { Music group n (\%) / mean } \\
\text { (SD) }\end{array}$ & $\begin{array}{l}\text { Control group n (\%) / mean } \\
\text { (SD) }\end{array}$ & $\begin{array}{l}p \text { - } \\
\text { value }\end{array}$ \\
\hline \multicolumn{5}{|l|}{ Gender } \\
\hline Male & $4 \mid(5 I .2)$ & $21(52.5)$ & $20(50)$ & 0.823 \\
\hline Female & $39(48.8)$ & $19(47.5)$ & $20(50)$ & \\
\hline Age, years & & $57.68(11.07)$ & $57.68(11.92)$ & 0.999 \\
\hline \multicolumn{5}{|l|}{ Education } \\
\hline Primary school & $29(36.2)$ & $12(30)$ & $17(42.5)$ & 0.245 \\
\hline Secondary school or above & $51(63.8)$ & $28(70)$ & $23(57.5)$ & \\
\hline \multicolumn{5}{|l|}{ Living } \\
\hline Lived alone & $7(8.8)$ & $5(12.5)$ & $2(5)$ & 0.432 \\
\hline Living with families & $73(91.2)$ & $35(87.5)$ & $38(95)$ & \\
\hline \multicolumn{5}{|l|}{ Colonoscopy experience } \\
\hline Yes & $37(46.2)$ & $16(40)$ & $21(52.5)$ & 0.262 \\
\hline No & $43(53.8)$ & $24(60)$ & $19(47.5)$ & \\
\hline \multicolumn{5}{|l|}{ Personal history of cancer } \\
\hline Yes & $15(18.8)$ & $8(20)$ & $7(17.5)$ & 0.775 \\
\hline No & $65(81.2)$ & $32(80)$ & $33(82.5)$ & \\
\hline \multicolumn{5}{|l|}{ Family history of cancer } \\
\hline Yes & $16(20)$ & $10(25)$ & $6(15)$ & 0.264 \\
\hline No & $64(80)$ & $30(75)$ & $34(85)$ & \\
\hline \multicolumn{5}{|l|}{$\begin{array}{l}\text { Regular follow up (chronic } \\
\text { disease) }\end{array}$} \\
\hline Yes & $32(40)$ & $14(35)$ & $18(45)$ & 0.361 \\
\hline No & $48(60)$ & $26(65)$ & $22(55)$ & \\
\hline \multicolumn{5}{|l|}{ Regular medication taking } \\
\hline Yes & $30(37.5)$ & $13(32.5)$ & $17(42.5)$ & 0.356 \\
\hline No & $50(62.5)$ & $27(67.5)$ & $23(57.5)$ & \\
\hline \multicolumn{5}{|l|}{ Clinical characteristic } \\
\hline Trait anxiety (T0) & & $39.00(7.55)$ & $39.30(9.19)$ & 0.874 \\
\hline
\end{tabular}

Notes: Independent $t$-test; Chi-square test were used for this study. T0 presented as anxiety was measured after consent for study group. Statistical not significance when $p>0.05$.

lengthening the time of music listening should be considered before colonoscopy.

No significant difference was found regarding the experience of pain between the two groups. One possible explanation for this finding is that pain assessment was not performed immediately after colonoscopy, which may have recall bias.

Several randomized controlled trials found that the music intervention would lower the desire for sedative and analgesic medication use. ${ }^{37}$ This study also found that the patients of the music group required less additional sedative and analgesic medication during colonoscopy than the control group, although a statistical significance was not reached. It might be due to the small sample size or the procedure is too short.
The results in our study did not reveal a significant impact on physiological parameters which is consistent with many studies. ${ }^{4,8,15,16}$ This may be due to individual differences in responding to music. The effects of music on physiological responses might be enhanced by the participants' musical preferences and musical training. ${ }^{4,22,23}$ Thus, allowing patients to choose their preferred music should be recommended.

In summary, these findings demonstrate that music provides benefit to aging patients undergoing colonoscopy and the use of music as an adjuvant to minimal sedation could enhance patients' satisfaction and potentially reduce drug-related complications 
Table 3 Summary of study results

\begin{tabular}{|c|c|c|c|}
\hline Variables & $\begin{array}{l}\text { Music group } \\
\text { mean } \pm \text { SD } / \\
n(\%)\end{array}$ & $\begin{array}{l}\text { Control } \\
\text { group mean } \\
\pm \text { SD/ n (\%) }\end{array}$ & $\begin{array}{l}P \text { - } \\
\text { value } \\
(2- \\
\text { tailed) }\end{array}$ \\
\hline $\begin{array}{l}\text { Heart rate (bpm) } \\
\text { T0 } \\
\text { TI } \\
\text { T2 }\end{array}$ & $\begin{array}{l}75.05 \pm 10.24 \\
69.45 \pm 14.83 \\
66.63 \pm 10.33\end{array}$ & $\begin{array}{l}77.85 \pm 10.34 \\
71.57 \pm 13.90 \\
71.50 \pm 12.93\end{array}$ & 0.438 \\
\hline $\begin{array}{l}\text { Systolic blood } \\
\text { pressure (SBP) } \\
\text { (mmHg) } \\
\text { T0 } \\
\text { TI } \\
\text { T2 }\end{array}$ & $\begin{array}{l}126.30 \pm 1 \mid .20 \\
\mid 22.85 \pm 21.27 \\
\mid 20.28 \pm 12.72\end{array}$ & $\begin{array}{l}126.80 \pm 10.57 \\
121.92 \pm 18.94 \\
120.88 \pm 18.36\end{array}$ & 0.937 \\
\hline $\begin{array}{l}\text { Diastole blood } \\
\text { pressure (DBP } \\
\text { (mmHg) } \\
\text { T0 } \\
\text { TI } \\
\text { T2 }\end{array}$ & $\begin{array}{l}80.52 \pm 7.48 \\
65.38 \pm 15.03 \\
74.10 \pm 11.48\end{array}$ & $\begin{array}{l}79.05 \pm 8.64 \\
63.65 \pm 12.36 \\
73.57 \pm 11.35\end{array}$ & 0.891 \\
\hline $\begin{array}{l}\text { Procedure satis- } \\
\text { faction }(0-10 \mathrm{~cm})\end{array}$ & $8.57 \pm 1.23$ & $7.83 \pm 1.91$ & 0.043 \\
\hline $\begin{array}{l}\text { Satisfaction with } \\
\text { pain management } \\
(0-10 \mathrm{~cm})\end{array}$ & $8.28 \pm 1.46$ & $7.35 \pm 2.49$ & 0.045 \\
\hline $\begin{array}{l}\text { Use music next } \\
\text { time } \\
\text { Yes } \\
\text { No }\end{array}$ & $\begin{array}{l}39(97.5) \\
\mathrm{I}(2.5)\end{array}$ & $\begin{array}{l}28(70) \\
12(30)\end{array}$ & 0.001 \\
\hline $\begin{array}{l}\text { State anxiety } \\
\text { (score 20-80) } \\
\text { Before } \\
\text { colonoscopy } \\
\text { After } \\
\text { colonoscopy }\end{array}$ & $\begin{array}{l}37.88 \pm 11.47 \\
30.80 \pm 6.60\end{array}$ & $\begin{array}{l}39.13 \pm 10.69 \\
30.05 \pm 5.91\end{array}$ & $\begin{array}{l}0.615 \\
0.594\end{array}$ \\
\hline Pain $(0-10 \mathrm{~cm})$ & $3.24 \pm 2.72$ & $3.37 \pm 3.07$ & 0.830 \\
\hline $\begin{array}{l}\text { Additional } \\
\text { sedation } \\
\text { Yes } \\
\text { No }\end{array}$ & $\begin{array}{l}6(15) \\
34(85)\end{array}$ & $\begin{array}{l}\text { II (27.5) } \\
29(75.5)\end{array}$ & 0.172 \\
\hline $\begin{array}{l}\text { Additional } \\
\text { analgesic } \\
\text { Yes } \\
\text { No }\end{array}$ & $\begin{array}{l}7(17.5) \\
33(82.5)\end{array}$ & $\begin{array}{l}14(35) \\
26(65)\end{array}$ & 0.075 \\
\hline
\end{tabular}

Notes: Repeated measures of analysis of variance; Chi-square test. Bold values denote statistical significance where $p<0.05$. T0: baseline; TI: 5 minutes after commencement of colonoscopy; T2: 30 minutes after completion of colonoscopy.

\section{Limitations and implications}

There are several limitations in this study. First, only a single setting was used to evaluate the intervention's effectiveness. The experiences of patients at other settings might not be similar, which limits the generalizability of the study findings. Second, the attending physicians were not blinded to group assignment as they can see the earphone for the intervention group, which may have affected their decision to give the patients more or less sedation. Finally, the patients were required to recall the pain they felt during the procedure, which may have a risk of bias in recall.

As recommendations for future studies, a large scale multi-center study should be conducted. Procedure time, comments from doctors and nurses and cost of the intervention should also be elicited to determine the costeffectiveness.

\section{Conclusion}

This study provides some evidence to support the practice of music intervention to enhance patients' satisfaction with procedure and pain management, Moreover, the majority of patients indicated they would want to have music next time. Thus, this simple and non-pharmacological method should be incorporated in the routine care and offer to every colonoscopy patient. Moreover, the results can also assist health care professionals in the design of music interventions for further study.

\section{Acknowledgments}

The authors would like to thank the Chief of Service and Nurse Manager for their permission to conduct this study in the EDU of Tuen Mum Hospital. Special thanks to all nurses and patients who offered support or participated in this study.

\section{Disclosure}

The authors report no conflicts of interest in this work.

\section{References}

1. Ko C, Chen Y, Kuan T, et al. Effect of music on level of anxiety in patients undergoing colonoscopy without sedation. J Chin Med Assoc. 2017, 80(3):154-160. doi:10.1016/j.jcma.2016.08.010.

2. Shafer LA, Walker JR, Waldman C, et al. Factors associated with anxiety about colonoscopy: the preparation, the procedure, and the anticipated findings. Dig Dis Sci. 2018;63(3):610-618. doi:10.1007/ s10620-018-4912-Z

3. Trevisani L, Zelante A, Sartori S. Colonoscopy, pain and fears: is it an indissoluble trinomial? World J Gastrointest Endosc. 2014;6(6):227. doi:10.4253/wjge.v6.i6.227 
4. Bessissow T, Van Keerberghen C-A, Van Oudenhove L, et al. Anxiety is associated with impaired tolerance of colonoscopy preparation in inflammatory bowel disease and controls. J Crohns Colitis. 2013;7(11):e580-e587. doi:10.1016/j.crohns.2013.04.011

5. Parker J, Kennedy P. Factors predictive of distress in people awaiting a lower gastro-intestinal endoscopy. Psychol Health Med. 2010;15 (9):26-33. doi:10.1080/13548500903440221

6. Costa A, Montalbano LM, Orlando A, et al. Music for colonoscopy: a single-blind randomized controlled trial. Digestive Liver Dis. 2010;42:871-876. doi:10.1016/j.dld.2010.03.016

7. Ovayolu N, Ucan O, Pehlivan S, et al. Listening to Turkish classical music decreases patients' anxiety, pain, dissatisfaction and the dose of sedative and analgesic drugs during colonoscopy: a prospective randomized controlled trial. World $J$ Gastroenterol. 2006;12 (6):7532-7536

8. De Oliveira GS, Holl JL, McCarthy RJ, et al. Overestimation of mortality risk and preoperative anxiety in patients undergoing elective general surgery procedures: a propensity matched analysis. Int $J$ Surg. 2014;12(12):1473-1477. doi:10.1016/j.ijsu.2014.11.016

9. Robleda G, Sillero-Sillero A, Puig T, Gich I, Baños J-E. Influence of preoperative emotional state on postoperative pain following orthopedic and trauma surgery. Rev Lat Am Enfermagem. 2014;22(5):785-791.

10. Kühlmann AYR, de Rooij A, Kroese LF, van Dijk M, Hunink MGM, Jeekel J. Meta-analysis evaluating music interventions for anxiety and pain in surgery. Br J Surg. 2018;105(7):773-783. doi:10.1002/ bjs. 10853

11. Sharma VK, Nguyen CC, Crowell MD, Lieberman DA, de Garmo P, Fleischer DE. A national study of cardiopulmonary unplanned events after GI endoscopy. Gastrointest Endosc. 2007;66(1):27-34. doi:10.1016/j.gie.2006.12.040

12. Arrowsmith BB, Gerstman B, Fleischer DE, Benjamin SB. Results from the American Society for Gastrointestinal Endoscopy/U.S. Food and Drug Administration collaborative study on complication rates and drug use during gastrointestinal endoscopy. Gastrointestinal Endoscopy. 1991;37(4):421-427. doi:10.1016/S0016-5107(91) 70773-6

13. Walker JA. Emotional and psychological preoperative preparation in adults. $\mathrm{Br} J$ Nurs. 2002;11(8):567-575. doi:10.12968/ bjon.2002.11.8.10166

14. Chlan L, Evans D, Greenleaf M, Walker J. Effects of a single music therapy intervention on anxiety, discomfort, satisfaction, and compliance with screening guidelines in outpatients undergoing flexible sigmoidoscopy. Gastroenterol Nurs. 2000;23(4):148-156.

15. Hoya Y, Matsumura I, Fujita T, Yanaga K. The use of nonpharmacological interventions to reduce anxiety in patients undergoing gastroscopy in a setting with an optimal soothing environment. Gastroenterol Nurs. 2008;31(6):395-399. doi:10.1097/SGA.0b013e31818eb5c9

16. De Silva AP, Niriella MA, Nandamuni Y, et al. Effect of audio and visual distraction on patients undergoing colonoscopy: a randomized controlled study. Endosc Int Open. 2016;4:E1211-E14. doi:10.1055/ s-0042-117630

17. Hole J, Ball E, Meads C. Music as an aid for postoperative recovery in adults: asystematic review and meta-analysis. Lancet. 2015;386 (10004):1659-1671. doi:10.1016/S0140-6736(15)60169-6

18. Vaajoki A, Pietila AM, Kankkunen P, Vehvilainen-Julkunen K. Effects of listening to music on pain intensity and pain distress after surgery: an intervention. J Clin Nurs. 2012;21(5-6):708-717. doi:10.1111/j.1365-2702.2011.03829.x
19. Hayes A, Buffum M, Lanier E, Rodahl E, Sasso C. A music intervention to reduce anxiety prior to gastrointestinal procedures. Gastroenterol Nurs. 2003;26(145-149):145. doi:10.1097/00001610200307000-00002

20. Spielberger CD, Gorsuch RC, Lushene RF. Manual of the State Trait Anxiety Inventory. Palo Alto, CA: Consulting psychologists Press; 1970.

21. Davidson CW. The effect of easy-listening background music on task-performance of fifth-grade children. J Educ Res. 1986, 80 (1):29-33. doi:10.1080/00220671.1986.10885717.

22. Harikumar R, Raj M, Paul A, et al. Listening to music decreases needs for sedative medication during colonoscopy: a randomized controlled trial. Indian Soc Gastroenterol. 2006;25(1):3-5.

23. Martindale F, Mikocka-Walus AA, Walus BP, Keage H, Andrews JM. The effects of a designer music intervention on patients' anxiety, pain, and experience of colonoscopy. Gastroenterol Nurs. 2014;37 (5):338-342. doi:10.1097/SGA.0000000000000066

24. Davis WB, Thaut MH. The influences of preferred relaxing music on measures of state anxiety, relaxation and physiological responses. $J$ Music Ther. 1989;26(4):168-187. doi:10.1093/jmt/26.4.168

25. Lazarus R, Folkman S. Stress, Appraisal, and Coping. New York: Springer Pub; 1984.

26. Mackay C, Pakenham KI. Identification of stress and coping risk and protective factors associated with changes in adjustment to caring for an adult with mental illness. J Clin Psychol. 2011;67(10):1064-1079. doi: $10.1002 /$ jclp.20829

27. Scott A. Managing anxiety in ICU patients: the role of pre-operative information provision. Nurs Crit Care. 2004;9(2):72-79.

28. Nilsson U. The anxiety- and pain-reducing effects of music interventions: a systematic review. Aorn J. 2008;87(4):780-807. doi:10.1016/ j.aorn.2007.09.013

29. Schulz KF, Altman DG, Moher D; CONSORT Group. CONSORT 2010 statement: updated guidelines for reporting parallel group randomised trials. PLoS Med. 2010;7:e1000251. doi:10.1371/journal. pmed.1000251

30. Lee I 25 th cluster clinical audit sharing meeting. Hospital authority: Tuen Mum Hospital

31. Hertzog MA. Considerations in determining sample size for pilot studies. Res Nurs Health. 2008;31(2):180-191. doi:10.1002/ nur. 20247

32. Shek DTL. The factorial structure of the Chinese version of the state-trait anxiety inventory: a confirmatory factor analysis. Psychol Edu Meas. 1991;51(4):985-997. doi:10.1177/ 001316449105100418

33. Shek DTL. The Chinese version of the state-trait anxiety inventory: its relationship to different measures of psychological well-being. $J$ Clin Psychol. 1993;49(3):349-358.

34. Huskisson EC. Measurement of pain. Lancet. 1974;2(7889):11271131.

35. Kersten P, White PJ, Tennant A. Is the pain visual analogue scale linear and responsive to change? An exploration using RASCH analysis. PLoS One. 2014;9(6):e99485. doi:10.1371/journal.pone.0099485

36. Bodian CA, Freedman G, Hossain S, Eisenkraft JB, Beilin Y. The visual analog scale for pain: clinical significance in postoperative patients. Anesthesiology. 2001;95(6):1356-1361.

37. Bjorkman I, Karlsson F, Lundberg A, Frisman GH. Gender differences when using sedative music during colonoscopy. Gastroenterol Nurs. 2013;36(1):14-20. doi:10.1097/ SGA.0b013e 31827c4c80 


\section{Publish your work in this journal}

Clinical Interventions in Aging is an international, peer-reviewed journal focusing on evidence-based reports on the value or lack thereof of treatments intended to prevent or delay the onset of maladaptive correlates of aging in human beings. This journal is indexed on PubMed Central, MedLine, CAS, Scopus and the Elsevier

Bibliographic databases. The manuscript management system is completely online and includes a very quick and fair peer-review system, which is all easy to use. Visit http://www.dovepress.com/ testimonials.php to read real quotes from published authors. 